\title{
Corrigendum
}

\section{Effect of Cigarette Smoking on a Marker for Neuroinflammation: A [ "C]DAAIl06 Positron Emission Tomography Study}

Arthur L Brody, Robert Hubert, Ryutaro Enoki, Lizette Y Garcia, Michael S Mamoun, Kyoji Okita, Edythe D London, Erika L Nurmi, Lauren C Seaman and Mark A Mandelkern

Neuropsychopharmacology (2018) 43, 925; doi:10.1038/npp.2017.261

Correction to: Neuropsychopharmacology (2017) 42, 16301639; doi:10.1038/npp.2017.48; published online 29 March 2017
Following publication, the authors reported that the data in Table 2 (page 1634) and the upper limit of the color scale in Figure 2 (page 1635) should be multiplied by 5 . All other results/statistics and conclusions are unchanged. 